\title{
Correction to: Governed by the cycle: interest rate sensitivity of emerging market corporate debt
}

\author{
Mariya Gubareva ${ }^{1,2,3}$ (D) Maria Rosa Borges ${ }^{4,5}$ (D) \\ ๑) Springer Science+Business Media, LLC, part of Springer Nature 2021

\section{Correction to: Annals of Operations Research https://doi.org/10.1007/s10479-021-03972-x}

Affiliations for author Mariya Gubareva were missing/incorrectly published in the article and needs to be corrected.

Publisher's Note Springer Nature remains neutral with regard to jurisdictional claims in published maps and institutional affiliations.

The original article can be found online at https://doi.org/10.1007/s10479-021-03972-x.

Maria Rosa Borges

mrborges@iseg.ulisboa.pt

Mariya Gubareva

mgubareva@iscal.ipl.pt

1 ISCAL - Lisbon Accounting and Business School/Instituto Politécnico de Lisboa, Av. Miguel Bombarda, 20, 1069-035 Lisbon, Portugal

2 SOCIUS/CSG (Research in Social Sciences and Management), Rua Miguel Lupi, 20, 1249-078 Lisbon, Portugal

3 National Research University Higher School of Economics/Centre for Financial Research \& Data Analytics, Pokrovsky Blv. 11, Room T-408, 109028 Moscow, Russian Federation

4 ISEG - Lisbon School of Economics and Management/Universidade de Lisboa, Rua do Quelhas, 6, 1200-781 Lisbon, Portugal

5 UECE - Research Unit on Complexity and Economics, Rua Miguel Lupi, 20, 1249-078 Lisbon, Portugal 